\title{
Development of Lipid-Based Gastroretentive Delivery System for Gentian Extract by Double Emulsion-Melt Dispersion Technique
}

\author{
Jelena Mudrić ${ }^{1, *}$, Katarina Šavikin ${ }^{1}$, Ljiljana Đekić ${ }^{2}$, Stefan Pavlović ${ }^{3}$, Ivana Kurćubić ${ }^{2}$, Svetlana Ibrić ${ }^{2}$ (D) \\ and Jelena Đuriš ${ }^{2}$ \\ 1 Institute for Medicinal Plants Research “Dr. Josif Pančić”, Tadeuša Košćuška 1, 11000 Belgrade, Serbia; \\ ksavikin@mocbilja.rs \\ 2 Department of Pharmaceutical Technology and Cosmetology, Faculty of Pharmacy, University of Belgrade, \\ Vojvode Stepe 450, 11221 Belgrade, Serbia; ljiljanadjekic@gmail.com (L.Đ.); \\ ivana.kurcubic@pharmacy.bg.ac.rs (I.K.); svetlana.ibric@pharmacy.bg.ac.rs (S.I.); \\ jelena.djuris@pharmacy.bg.ac.rs (J.Đ.) \\ 3 Institute of Chemistry, Technology, and Metallurgy-National Institute for the Republic of Serbia, \\ University of Belgrade, Njegoševa 12, 11001 Belgrade, Serbia; stefan.pavlovic@ihtm.bg.ac.rs \\ * Correspondence: jmudric@mocbilja.rs
}

check for

updates

Citation: Mudrić, J.; Šavikin, K.; Đekić, L.; Pavlović, S.; Kurćubić, I.; Ibrić, S.; Đuriš, J. Development of Lipid-Based Gastroretentive Delivery System for Gentian Extract by Double Emulsion-Melt Dispersion Technique. Pharmaceutics 2021, 13, 2095. https:// doi.org/10.3390/pharmaceutics13122095

Academic Editor: Nadia Passerini

Received: 29 October 2021

Accepted: 26 November 2021

Published: 6 December 2021

Publisher's Note: MDPI stays neutra with regard to jurisdictional claims in published maps and institutional affiliations.

Copyright: (C) 2021 by the authors Licensee MDPI, Basel, Switzerland. This article is an open access article distributed under the terms and conditions of the Creative Commons Attribution (CC BY) license (https:// creativecommons.org/licenses/by/ $4.0 /)$.

\begin{abstract}
Gentian (Gentiana lutea L., Gentianaceae) root extract (GRE) is used for the treatment of gastrointestinal disorders. However, its bioactive potential is limited in conventional forms due to the low bioavailability and short elimination half-life of the dominant bioactive compound, gentiopicroside. The aim of study was to encapsulate GRE in the lipid-based gastroretentive delivery system that could provide high yield and encapsulation efficiency, as well as the biphasic release of gentiopicroside from the tablets obtained by direct compression. Solid lipid microparticles (SLM) loaded with GRE were prepared by freeze-drying double (W/O/W) emulsions, which were obtained by a multiple emulsion-melt dispersion technique, with GRE as the inner water phase, Gelucire ${ }^{\circledR}$ $39 / 01$ or $43 / 01$, as lipid components, with or without the addition of porous silica (Sylysia ${ }^{\circledR} 350$ ) in the outer water phase. Formulated SLM powders were examined by SEM and mercury intrusion porosimetry, as well as by determination of yield, encapsulation efficiency, and flow properties. Furthermore, in vitro dissolution of gentiopicroside, the size of the dispersed systems, mechanical properties, and mucoadhesion of tablets obtained by direct compression were investigated. The results have revealed that SLM with the macroporous structure were formulated, and, consequently, the powders floated immediately in the acidic medium. Formulation with porous silica (Sylysia ${ }^{\circledR} 350$ ) and Gelucire ${ }^{\circledR} 43 / 01$ as a solid lipid was characterized with the high yield end encapsulation efficiency. Furthermore, the mucoadhesive properties of tablets obtained by direct compression of that formulation, as well as the biphasic release of gentiopicroside, presence of nanoassociates in dissolution medium, and optimal mechanical properties indicated that a promising lipid-based gastroretentive system for GRE was developed.
\end{abstract}

Keywords: solid lipid microparticles; SLM; gastroretentive system; Gelucire 43/01; Gelucire 39/01; Sylysia 350; gentiopicroside; double (W/O/W) emulsion; mucoadhesion; direct compression; biphasic release

\section{Introduction}

Yellow gentian (Gentiana lutea L., Gentianaceae) root is officially listed in the European and many national Pharmacopoeias [1]. Gentian root extract is used for the treatment of numerous gastrointestinal disorders, such as loss of appetite, functional dyspepsia, and liver dysfunction [2,3]. The main bioactive compounds of gentian root extract are secoiridoids, particularly gentiopicroside as a dominant compound, with manifested gastroprotective, choleretic, hepatoprotective, and anti-inflammatory activities [4]. However, the bioactive 
potential of gentian extract is limited in conventional forms due to the low bioavailability and short elimination half-life of gentiopicroside [5]. In addition, a local gastric effect of gentian extract was reported [6], indicating that prolonged release of gentiopicroside in the stomach could be beneficial.

Consequently, in order to improve the bioavailability and effectiveness, as well as patient compliance, it is necessary to enable the release of an initial, effective dose of gentian extract, followed by further sustained release at the place of action (stomach). This would allow improved absorption of the gentian extract active compounds. Since the effectiveness of gastroretentive delivery systems is influenced by numerous factors (gastric fluid level, presence of food, and gastric contents), the combination of different gastroretention strategies such as floating and mucoadhesion is desired [7] in order to increase the residence time of the gentian extract in the stomach. Lately, solid lipid microparticles have been applied as a carrier for the bioactive compound site-specific delivery [8]. Furthermore, this type of carrier provides good in vivo tolerability, adequate stability, and increased bioavailability, with quite low production costs and feasibility of large-scale production [9]. Lipid-based particles are commonly used for the encapsulation of lipophilic active compounds, whereas the inefficient incorporation of hydrophilic compounds, such as gentiopicroside, has been considered as their main disadvantage. However, the double emulsion $(\mathrm{W} / \mathrm{O} / \mathrm{W})$ method could be used to overcome this limitation by incorporating hydrophilic active compounds or extracts in the inner water phase $[10,11]$. It is known that the formulation of double emulsions could be a challenging task because of their low thermodynamic stability [12]. Therefore, the selection of lipids, as well as lipophilic and hydrophilic emulsifiers as essential components of $\mathrm{W} / \mathrm{O} / \mathrm{W}$ emulsions are the critical steps in the formulation of solid lipid microparticles for stomach-specific delivery, i.e., lipid-based gastroretentive system. Solid lipids, Gelucire ${ }^{\circledR} 43 / 01$ and Gelucire ${ }^{\circledR} 39 / 01$, are promising materials in the formulation of gastroretentive delivery systems due to their high lipophilicity and low density, whereas their low melting temperatures (approximately $43^{\circ} \mathrm{C}$ and $39^{\circ} \mathrm{C}$, respectively) are considered as favorable, to prevent thermal degradation of the bioactive compounds from the gentian extract during the $\mathrm{W} / \mathrm{O} / \mathrm{W}$ emulsion processing $[13,14]$. Furthermore, their triglyceride-based nature promotes contact with intestinal membranes, increases the solubilization and formation of triglyceride-rich chylomicrons, and reduces gastric emptying, and, thereby, improves the absorption of bioactive compounds [15]. Lipophilic emulsifiers such as polyglycerol ester of polyricinoleic acid (PGPR) and Spans ${ }^{\circledR}$ (sorbitan esters) are required to stabilize the $\mathrm{W} / \mathrm{O}$ interface, whereas emulsifiers with higher HLB values, such as Tweens ${ }^{\circledR}$ (polysorbates), lecithin and proteins, are used as stabilizers of the $\mathrm{O} / \mathrm{W}$ interface [10]. Generally, formulations containing lipids and surfactants in contact with the aqueous media could undergo the process of dissolution and molecular self-assembly, i.e., they spontaneously interact to form organized nanostructures such as micelles, mixed micelles, or more complex organized nanostructures. In addition, the bioavailability of encapsulated bioactive compounds increases as the lipid droplet size decreases, indicating that the size of dispersed systems could influence the effectiveness of the final product.

However, the fact that dosage forms resulting from $\mathrm{W} / \mathrm{O} / \mathrm{W}$ emulsions are usually liquids presents a drawback from the patient and industry point of view. Furthermore, the literature data support the use of gentian extract in solid dosage forms [6]. Therefore, it could be vital to transform liquid W/O/W emulsion into a powder form. Moreover, directly compressible powders are preferred in the pharmaceutical industry, while it is possible to produce tablets by using the direct compression method, which is simple, environmentally friendly (solvent/heat-free), and time/cost-effective. It is hypothesized that the properties of a lipid-based gastroretentive delivery system loaded with gentian extract could be improved by the incorporation of highly porous micronized silica (Sylysia ${ }^{\circledR} 350$ ), which has been widely employed as a powdering agent and carrier for liquid formulations [16].

Therefore, the objective of this study was to develop a lipid-based gastroretentive delivery system loaded with the gentian extract that could provide high yield and encapsulation efficiency, as well as the biphasic release of gentiopicroside from tablets obtained 
by direct compression of powder obtained by the freeze-drying of double emulsions with gentian extract as the inner water phase and Gelucire ${ }^{\circledR} 39 / 01$ or $43 / 01$, as lipid components, without the addition of organic solvents.

\section{Materials and Methods}

\subsection{Materials}

Gentian (Gentiana lutea, Gentianaceae) roots were purchased from the Institute for Medicinal Plants Research "Dr. Josif Pančić" (Belgrade, Serbia). Gelucire ${ }^{\circledR} 43 / 01$ and Gelucire ${ }^{\circledR}$ 39/01 were obtained as gift samples from Gattefossé ${ }^{\circledR}$ (Saint-Priest, France). Polyglycerol polyricinoleate was obtained as a gift sample from Palsgaard ${ }^{\circledR}$ (Juelsminde, Denmark). Trehalose dihydrate was purchased from TCI Chemicals (Tokyo, Japan). Span ${ }^{\circledR} 80$ (sorbitan oleate), Tween ${ }^{\circledR} 80$ (polysorbate 80 ), Tween ${ }^{\circledR} 20$ (polysorbate 20), and sodium chloride were obtained from Merck Co., Germany, while sodium alginate was purchased from Fisher Scientific, soybean lecithin was obtained from Serva Chemical Co. (Heidelberg, Germany), Sylysia ${ }^{\circledR} 350$ was obtained from Fuji Silysia chemical ltd. (Kasugai Aichi, Japan). For the mucoadhesion evaluation, the mucin from a porcine stomach, Type II (Sigma-Aldrich, Shanghai, China) was used. All other chemicals were of analytical grade, including orthophosphoric acid (Sigma-Aldrich Chemie GmbH, Münich, Germany), acetonitrile (Merck, Darmstadt, Germany). Ultra-pure water was prepared using a Milli-Q purification system (Millipore, Guyancourt, France). Gentiopicroside standard was obtained from ChromaDex (Los Angeles, CA, USA).

\subsection{Gentian Extract Preparation}

Gentian (Gentiana lutea, Gentianaceae) root extraction was performed in conical percolator by standard percolation procedure with ethanol as extraction solvent $(50 \%, v / v)$ while solid to solvent ratio was $1: 2(\mathrm{~g} / \mathrm{mL})$. Consequently, ethanol was evaporated by using a rotary vacuum evaporator (IKA ${ }^{\circledR} \mathrm{RV} 05$, Staufen, Germany), and the obtained liquid extract was filtrated and stored in a refrigerator in the dark bottle.

\subsection{Preparation of Double W/O/W Emulsion}

Double emulsions were prepared according to the multiple (double) emulsion-melt dispersion technique as summarized in Figure 1. Firstly, preheated water phase (liquid gentian extract, sodium alginate, and sodium chloride) was added dropwise to the melted lipid phase (solid lipid: Gelucire ${ }^{\circledR} 43 / 01$ or Gelucire ${ }^{\circledR} 39 / 01$ and lipophilic emulsifier) according to the composition represented in Table 1, with constant stirring on a magnetic stirrer at $500 \mathrm{rpm}\left(\mathrm{IKA}{ }^{\circledR} \mathrm{RCT}\right.$ standard, Staufen, Germany) at temperature $\left(5-10^{\circ} \mathrm{C}\right)$ above the lipid melting point. In the preliminary study, primary emulsion $(\mathrm{W} / \mathrm{O})$ was formulated with Span ${ }^{\circledR} 80$ or PGPR as lipophilic emulsifiers. The obtained primary emulsion (W/O) was homogenized at 15,000 rpm for $3 \mathrm{~min}$ by using a high-shear homogenizer (Ultra-Turrax, $\mathrm{IKA}^{\circledR}$, Staufen, Germany), while the temperature was constantly in the range presented in Table 1.

In the second step, hot (temperature indicated in Table 1) primary emulsion (W/O) with PGPR as lipophilic emulsifier was dispersed in the outer water phase containing a hydrophilic emulsifier, sodium alginate, sodium chloride, trehalose with or without Sylysia ${ }^{\circledR} 350$ (Table 2). The temperatures of emulsions with Gelucire ${ }^{\circledR} 39 / 01$ as solid lipid in the primary emulsions were in the range $44-49{ }^{\circ} \mathrm{C}$, whereas the temperatures of emulsions with Gelucire ${ }^{\circledR} 43 / 01$ were in the range $48-53^{\circ} \mathrm{C}$. In the preliminary study, Tween ${ }^{\circledR} 80$, Tween ${ }^{\circledR} 20$, or lecithin were used as hydrophilic emulsifiers. Trehalose was used in all formulations as a cryoprotectant. Subsequently, emulsion $(\mathrm{W} / \mathrm{O} / \mathrm{W})$ was homogenized at $3000 \mathrm{rpm}$ for $4.5 \mathrm{~min}$ by a high-shear homogenizer (Ultra-Turrax, IKA ${ }^{\circledR}$, Staufen, Germany). Furthermore, double emulsion $(\mathrm{W} / \mathrm{O} / \mathrm{W})$ was continually stirred by a laboratory mixer (Heidolph RZR 2020, Heidolph Elektro GmbH \& Co., KG, Kelheim, Germany) until the temperature of the prepared $\mathrm{W} / \mathrm{O} / \mathrm{W}$ emulsion was approximately $25^{\circ} \mathrm{C}$. 


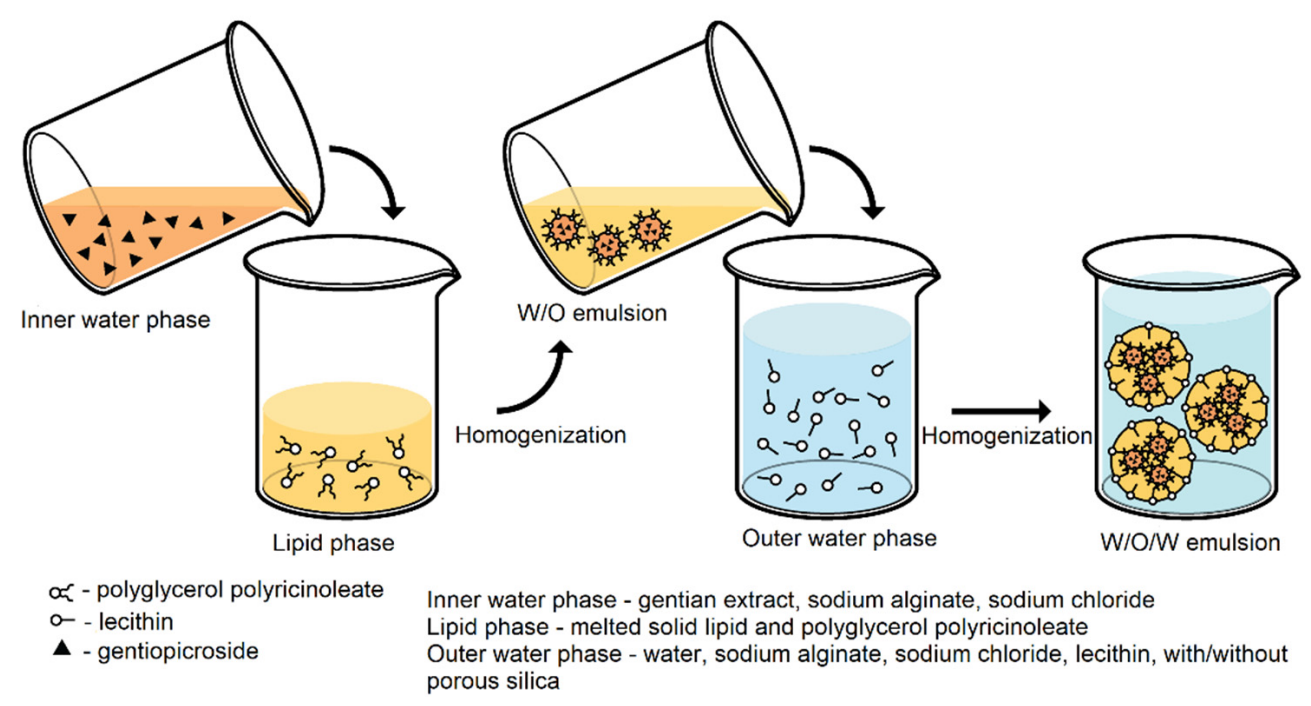

Figure 1. Process scheme.

Table 1. A-D: The primary (W/O) emulsion composition.

\begin{tabular}{|c|c|c|c|c|}
\hline & $\mathbf{A}$ & B & $\mathrm{C}$ & $\mathbf{D}$ \\
\hline Gentian extract (\%) & 66.5 & 66.5 & 66.5 & 66.5 \\
\hline Sodium alginate (\%) & 1.3 & 1.3 & 1.3 & 1.3 \\
\hline Sodium chloride (M) & 0.05 & 0.05 & 0.05 & 0.05 \\
\hline Gelucire ${ }^{\circledR} 39 / 01(\%)$ * & 26.9 & 26.9 & / & / \\
\hline Gelucire $^{\circledR} 43 / 01(\%)^{* *}$ & / & / & 26.9 & 26.9 \\
\hline Lipophilic emulsifier (\%) *** & 5.0 & 5.0 & 5.0 & 5.0 \\
\hline
\end{tabular}

* Emulsions were prepared
polyglycerol polyricinoleate.

Table 2. A-D: Double (W/O/W) emulsion composition.

\begin{tabular}{ccccc}
\hline & A & B & C & D \\
\hline Primary emulsion with PGPR (\%) & 19.8 & 19.8 & 19.8 & 19.8 \\
Sodium alginate (\%) & 2 & 2 & 2 & 2 \\
Sodium chloride (\%) & 0.05 & 0.2 & 0.2 & 0.2 \\
Hydrophilic emulsifier (\%) & 1.6 & 1.6 & 1.6 & 1.6 \\
Trehalose (\%) & 7.9 & 7.9 & 7.9 & 7.9 \\
Sylysia ${ }^{\circledR}$ 350 (\%) & $/$ & 1.0 & $/$ & 1.0 \\
Purified water to (\%) & 100.0 & 100.0 & 100.0 & 100.0
\end{tabular}

${ }^{*}$ Corresponding primary emulsion was marked with the same letter in Table 1; PGPR-polyglycerol polyricinoleate. ${ }^{*}$ Tween ${ }^{\circledR} 80$, Tween ${ }^{\circledR} 20$, or lecithin.

\subsection{Characterization of Double Emulsions}

\subsubsection{Conductometric Analysis}

The conductivity of prepared samples was measured by using a conductivity meter (Radiometer, Copenhagen, Denmark) $24 \mathrm{~h}$ after preparation at $22 \pm 2{ }^{\circ} \mathrm{C}$. Each sample was analyzed in triplicate.

\subsubsection{Centrifugation Test}

The stability of prepared samples (A-D) with PGPR as lipophilic emulsifier and lecithin as hydrophilic emulsifier was determined by centrifugation of double emulsion and by measuring the supernatant volume $(\mathrm{mL})$. The samples were taken into centrifuge tubes and centrifuged (Hermle Z206A, Labortechnik GmbH, Wehingen, Germany) for $15 \mathrm{~min}$ at $5000 \mathrm{rpm}$ at $22 \pm 2{ }^{\circ} \mathrm{C}$. Each sample was analyzed in triplicate. 


\subsubsection{Microscopic Analysis}

Microscopic analysis of the investigated emulsions after carefully diluting samples with purified water was conducted by using an Optical microscope (Olympus ${ }^{\circledR}$ BX 41, Olympus Optical Co., Tokyo, Japan).

\subsection{Preparation of Solid Lipid Microparticles}

Prepared double emulsions (A-D) with PGPR as lipophilic emulsifier and lecithin as hydrophilic emulsifier were lyophilized by the in-house method developed in the PVPCentre for Lyophilization (Valjevo, Serbia). Furthermore, liquid gentian extract obtained by the procedure described in Section 2.2 was dried under the same conditions in order to prepare gentian extract powder, which was compared with developed SLM formulations. Obtained freeze-dried materials were ground and stored in a desiccator.

\subsection{Characterization of Solid Lipid Microparticles}

\subsubsection{Scanning Electron Microscopy}

The morphology of dry gentian extract and solid lipid microparticles powders was estimated by using JEOL JSM-6390LV scanning electron microscope (JEOL USA, Inc., Peabody, MA, USA). Prior to the analysis, samples were coated with gold for $100 \mathrm{~s}$ under $30 \mathrm{~mA}$ ion current on BALTEC SCD 005 sputter coater (Balzers, Switzerland).

\subsubsection{Determination of the Encapsulation Efficiency}

Accurately weighed samples of solid lipid microparticles (80-100 mg) were placed in volumetric flasks with $2 \mathrm{~mL}$ of hot $\left(70-80{ }^{\circ} \mathrm{C}\right)$ purified water. Samples in the flasks were heated in a water bath at $70{ }^{\circ} \mathrm{C}$ and sonicated for $30 \mathrm{~min}$ to melt the lipid component. Afterwards, the samples were diluted to $5 \mathrm{~mL}$ with hot purified water and filtered $(0.45 \mu \mathrm{m}$ cellulose acetate membrane filters). The concentration of gentiopicroside in samples was determined by high-performance liquid chromatography (Section 2.6.3). Gentiopicroside encapsulation efficiency ( $E E)$ was calculated according to Equation (1) [14]. Each sample was analyzed in triplicate and the results were presented as mean \pm standard deviation. The differences among samples were tested by one-way ANOVA and subsequently estimated by Tukey's post hoc test. Statistical analysis was performed using the MS Office Excel v. 2010.

$$
E E=\frac{\text { Actual quantity of gentiopicroside entrapped in particles }}{\text { Theoretical quantity of gentiopicroside }} \times 100
$$

\subsubsection{High-Performance Liquid Chromatography}

Analyses were performed on Agilent 1200 RR HPLC instrument (Agilent, Waldbronn, Germany), on a reverse-phase Zorbax SB-C18 (Agilent, Waldbronn, Germany) analytical column ( $150 \mathrm{~mm} \times 4.6 \mathrm{~mm}$ i.d.; $5 \mu \mathrm{m}$ particle size) according to the previously described procedure [17]. Identification of the marker compound (gentiopicroside) was achieved by comparing their UV spectra and retention time with those from authentic standards, while the concentration was determined from the peak areas by using the equation for linear regression obtained from calibration curves (correlation coefficient was 0.998).

\subsubsection{Determination of Yield}

The yield was determined as the percentage of obtained microparticles mass $(A)$ with respect to the expected mass of total solids used for their production $(B)$. The solid content of liquid materials was determined after measuring dry residue on a moisture analyzer (Mettler Toledo HB43-S, Melbourne, Australia). Each sample was analyzed in triplicate. The differences among samples were tested by one-way ANOVA and subsequently estimated by Tukey's post hoc test. Statistical analysis was performed using the MS Office Excel v. 2010.

$$
\text { Yield }(\%)=\frac{A}{B} \times 100
$$




\subsubsection{Mercury Intrusion Porosimetry}

Mercury intrusion porosimetry measurements were performed in the fully automated conventional apparatus Carlo Erba Porosimeter 2000 (pressure range: 0.1-200 MPa; pores with a diameter within $7.5 \mathrm{~nm}$ and $15,000 \mathrm{~nm}$ ). The acquisition of the analysis data was performed using the Milestone Software 200. The measurements were conducted in two consecutive runs to remove potential suspicions of the presence of interparticle (voids) and intraparticle spaces, but also to indicate the dominant type of pores. The samples were evacuated for $2 \mathrm{~h}$ in a dilatometer placed in the Macropores Unit 120.

\subsubsection{Flow Properties Evaluation}

Flowability of the investigated powders was evaluated by calculating the Hausner ratio and the Compressibility index [1], according to Equations (3) and (4), where $V_{0}$ is unsettled apparent volume and $V f$ is the final tapped volume determined after tapping the powder by the tapped density tester (Stampfvolumeter, STAV 2003, Jel, Ludwigshafen, Germany). Each sample was analyzed in triplicate and the results were presented as mean \pm standard deviation.

$$
\begin{aligned}
\text { Hausner ratio } & =\frac{V o}{V f} \\
\text { Compressibility index } & =\frac{V o-V f}{V f} \times 100
\end{aligned}
$$

\subsubsection{Tablets Preparation and Determination of Mechanical Properties}

Tablets were prepared by direct compression of powdered solid lipid microparticles. Tableting properties were examined by using a benchtop single-punch tablet press Gamlen D series (Gamlen Tableting Limited, London, UK) equipped with a flat punch $(6 \mathrm{~mm})$. The samples (approximately $100 \mathrm{mg}$ of powder) were compressed at different loads (30 to $150 \mathrm{~kg})$, while compaction speed $(60 \mathrm{~mm} / \mathrm{min})$ and dwell time $(0.08 \mathrm{~s})$ were the same for each tablet sample. No lubricant was added before or during compression. For each phase of the tableting process (compression, detachment, and ejection) a force-displacement curve was generated by the instrument software, and the data were used to calculate the tensile strength, Equation (5); detachment stress, Equation (6); ejection stress, Equation (7) [18]. Tablet hardness and diameter were measured by using a hardness tester (Erweka ${ }^{\circledR} \mathrm{TBH}$ 125D, Erweka, Heusenstamm, Germany). Tablet thickness was estimated after the tablet ejection by the digital caliper. Each sample, compressed under defined load, was analyzed in triplicate and the results were presented as mean \pm standard deviation.

$$
\begin{gathered}
\sigma(\mathrm{MPa})=\frac{2 \times F}{\pi \times R \times t} \\
\text { Detachment stress }(\mathrm{MPa})=\frac{D \times 4}{R^{2} \times \pi} \\
\text { Ejection stress }(\mathrm{MPa})=\frac{E}{R \times \pi \times t}
\end{gathered}
$$

Tablet tensile strength $-\sigma$; force applied for tablet breaking $-F(N)$; the tablet diameter $-R$ $(\mathrm{mm})$; the tablet thickness $-t(\mathrm{~mm})$; the maximal force of detachment phase $-D(N)$; the maximal force of ejection phase $-E(\mathrm{~N})$.

\subsubsection{In Vitro Gentiopicroside Dissolution Testing}

Dissolution of gentiopicroside (marker compound in the gentian extract) from formulated solid lipid microparticles (in the form of tablets) and the freeze-dried gentian extract (in the form of powder) was tested. Gentian extract powder and solid lipid microparticles in the form of tablets (A-D) were tested using USP IV (Flow-through cell, CE7 smart, Sotax, Aesch, Switzerland) apparatus, at $37 \pm 0.5^{\circ} \mathrm{C}$, with a flow rate of $8 \mathrm{~mL} / \mathrm{min}$, during $6 \mathrm{~h}$, while dissolution medium was $0.1 \mathrm{M} \mathrm{HCl}(100 \mathrm{~mL})$. Samples were withdrawn and filtrated at $15,45,90,150,240,360 \mathrm{~min}$ and immediately replaced with a fresh medium. Equal volumes of filtrated samples $(2.5 \mathrm{~mL})$ were combined and used as a pooled sample of 
investigated formulations according to the procedure for Botanical dosage forms described in the United States Pharmacopeial Convention [19]. The concentration of dissolved gentiopicroside in those samples was determined by high-performance liquid chromatography (Section 2.6.3).

Furthermore, the model-independent index described by Moore and Flanner [20], known as the similarity factor $\left(f_{2}\right)$ was used in order to statistically demonstrate the differences between the dissolution profiles of investigated samples, according to Equation (8). A value of $f_{2}$ lower than 65 implies that the profiles are significantly different, while the value of $f_{2}$ in the range from 65 to 100 indicates similarity between the profiles of over $95 \%$ [21].

$$
f_{2}=50 \times \log \left\{\left[1+\frac{1}{n} \sum_{n=1}^{t}\left(R_{t}-T_{t}\right)^{2}\right]^{-0.5} \times 100\right\}
$$

where $n$ is the number of dissolution sampling times, $R_{t}$ and $T_{t}$ are the active compound (gentiopicroside) release percentage at each time for the reference and test sample, respectively.

\subsubsection{Kinetic Modeling of Gentiopicroside Release}

Gentiopicroside release kinetics were analyzed by using the data of a six-hour dissolution profile of each formulation and fitting into zero-order, first-order, Higuchi, and Korsmeyer-Peppas models. The highest correlation coefficient $\left(\mathrm{r}^{2}\right)$ value is indicative of the actual model of the release.

\subsubsection{Assessment of Dispersibility during In Vitro Dissolution}

In order to assess the dispersibility of the solid lipid microparticles (in the form of tablets), the size of the dispersed nanostructures in the dissolution medium $(0.1 \mathrm{M} \mathrm{HCl})$ was measured in the samples collected during the in vitro gentiopicroside dissolution testing of formulations A-D, at the first time point (after $15 \mathrm{~min}$ ) and the last (after $6 \mathrm{~h}$ ), using photon correlation spectroscopy (PCS). The size distribution was characterized by Zetasizer Nano ZS90 (Malvern Instruments, Malvern, UK) with the integrated He-Ne laser at $633 \mathrm{~nm}$ and scattered light detector at $90{ }^{\circ} \mathrm{C}$. The measurements were performed at $20 \pm 0.1^{\circ} \mathrm{C}$.

\subsubsection{Mucoadhesion Evaluation}

Mucoadhesion of tablets composed of formulated solid lipid microparticles was determined as a force required to separate the investigated tablet (5 samples for each formulation) from the mucin disk. Texture Analyzer Shimadzu EZ-LX (Shimadzu Corporation, Kyoto, Japan), with a $5 \mathrm{~kg}$ load cell and $10 \mathrm{~mm}$ aluminum cylindrical probe, was used to measure the force of adhesion. Before the analysis, each tablet was glued to the upper probe, whereas mucin disc was attached to the surface of the platform by cyanoacrylate glue. Mucin discs were prepared by compression of commercially available raw gastric porcine mucin $(250 \mathrm{mg})$ using a die of $13 \mathrm{~mm}$ in diameter. Afterward, the mucin disk was poured in $0.1 \mathrm{M} \mathrm{HCl}(2.5 \mathrm{~mL})$ heated up to $37^{\circ} \mathrm{C}$ for $4 \mathrm{~min}$. A force of $0.5 \mathrm{~N}$ was applied on the tablet for $60 \mathrm{~s}$ to ensure intimate contact between the tablet and the mucin disc, where the pre-test speed was $1 \mathrm{~mm} / \mathrm{s}$, the test speed of $0.5 \mathrm{~mm} / \mathrm{s}$, and the post-test speed of $0.5 \mathrm{~mm} / \mathrm{s}$. The obtained force-time curves were utilized to determine the force of adhesion, i.e., the force required to separate the tablet from the mucin disc, as an indicator of tablet mucoadhesion. The study was performed in 5 replicates for each formulation and the results were presented as mean \pm standard deviation. The differences among samples were tested by one-way ANOVA and subsequently estimated by Tukey's post hoc test. Statistical analysis was performed using MS Office Excel v. 2010. 


\section{Results and Discussion}

\subsection{Double Emulsions Development}

Critical parameters in the development of a stable $\mathrm{W} / \mathrm{O} / \mathrm{W}$ emulsion is the selection of the appropriate lipophilic $(\mathrm{W} / \mathrm{O})$ and hydrophilic $(\mathrm{O} / \mathrm{W})$ emulsifiers. Span ${ }^{\circledR} 80(5 \%)$ as a lipophilic low molecular emulsifier was first used for stabilization of the $\mathrm{W} / \mathrm{O}$ emulsion. However, formulations were unstable, and rapid phase separation was detected (approximately upon $5 \mathrm{~min}$ ). On the other hand, $\mathrm{W} / \mathrm{O}$ emulsions with a lipophilic polymeric emulsifier, PGPR (5\%), were stable during one month of storage at room temperature. This result was in accordance with the previous findings, where PGPR was able to interact more effectively with the oil phase than $\operatorname{Span}^{\circledR} 80$ and, consequently, to prevent droplets coalescence due to higher hydrophobicity [10]. Therefore, PGPR was chosen as an appropriate emulsifier for the stabilization of primary $(\mathrm{W} / \mathrm{O})$ emulsion. Furthermore, it is reported that the addition of biopolymers such as sodium alginate to the inner water phase provides the formation of a viscoelastic barrier, thus preventing coalescence, as a result of the interaction between polysaccharide and the lipophilic emulsifier [10]. Additionally, the primary emulsion thermodynamic stability could be improved by incorporating the electrolytes such as sodium chloride in the inner water phase since collision frequency and droplet sizes are reduced in that way due to a decrease in attractive forces between water droplets and reduction in interfacial tension [22,23]. For that reason, sodium alginate $(1.3 \%)$ and sodium chloride $(0.05 \mathrm{M})$ were added to the inner water phase. Furthermore, to ensure uniform osmotic pressure in the primary $(\mathrm{W} / \mathrm{O})$ and secondary $(\mathrm{W} / \mathrm{O} / \mathrm{W})$ emulsion, and to avoid diffusion between the inner and outer phase, sodium chloride and sodium alginate were also added to the outer water phase. In order to choose the optimal hydrophilic emulsifier, double emulsion with Tween ${ }^{\circledR} 80$, Tween ${ }^{\circledR} 20$, and lecithin were prepared. Immediately after processing, in the emulsions with Tween ${ }^{\circledR} 80$ and Tween ${ }^{\circledR}$ 20, phase separation was evident. On the other hand, double emulsions with lecithin (samples A-D) were stable during a week of refrigerated storage. Emulsions A-D were yellow and homogenous, and there were no changes in consistency and homogeneity, and phase separation was not detected after the centrifugation test. The conductivity of investigated emulsions A $(4.03 \pm 0.24 \mu \mathrm{S} / \mathrm{cm}), \mathrm{B}(4.28 \pm 0.31 \mu \mathrm{S} / \mathrm{cm}), \mathrm{C}(4.53 \pm 0.18 \mu \mathrm{S} / \mathrm{cm})$, and $\mathrm{D}(4.77 \pm 0.13 \mu \mathrm{S} / \mathrm{cm})$ indicates that the water phase was the external phase of the obtained emulsion. It is known that high conductivity suggests an $\mathrm{O} / \mathrm{W}$ or $\mathrm{W} / \mathrm{O} / \mathrm{W}$ emulsion, while a low conductivity $(<1 \mu \mathrm{S} / \mathrm{cm})$ could indicate a $\mathrm{W} / \mathrm{O}$ or $\mathrm{O} / \mathrm{W} / \mathrm{O}$ emulsion [24]. According to the microscopic analysis, the investigated emulsions with Gelucire ${ }^{\circledR} 43 / 01$ or Gelucire ${ }^{\circledR} 39 / 01$, as well as with or without Sylysia ${ }^{\circledR} 350$ were characterized as double $(\mathrm{W} / \mathrm{O} / \mathrm{W})$ emulsions with a complex inner structure inside oil droplets, i.e., microsphere (C type)-type double emulsions (Figure 2). It is known that the double emulsion type is significantly influenced by the type of hydrophilic surfactant and the concentration of hydrophobic surfactant. Furthermore, emulsions with a higher concentration of the hydrophobic surfactant are generally considered as microsphere-type double emulsions, which are more stable emulsions with higher encapsulation efficiency $[25,26]$.

\subsection{Solid Lipid Microparticles Characterization}

\subsubsection{Morphology}

The powders obtained after the freeze-drying of double emulsions were homogenous and yellow. The shape and size of formulated powders were analyzed by SEM. Obtained solid lipid particles (Figure 3) were characterized with amorphous structures, similar to flakes of varying size, likely as a result of the samples grinding. This shape is common for microparticles obtained by the freeze-drying process [27]. The particle size (diameter), even with some aggregation, was under $1000 \mu \mathrm{m}$, indicating that solid lipid microparticles were developed. Higher magnification of the samples revealed the porous structure of microparticles. It has been reported previously that pores in microparticles are formed due to the sublimation of ice crystals during freeze-drying [28]. On the other hand, dry gentian extract particles were spherical but pores were not detected (Figure 4). 


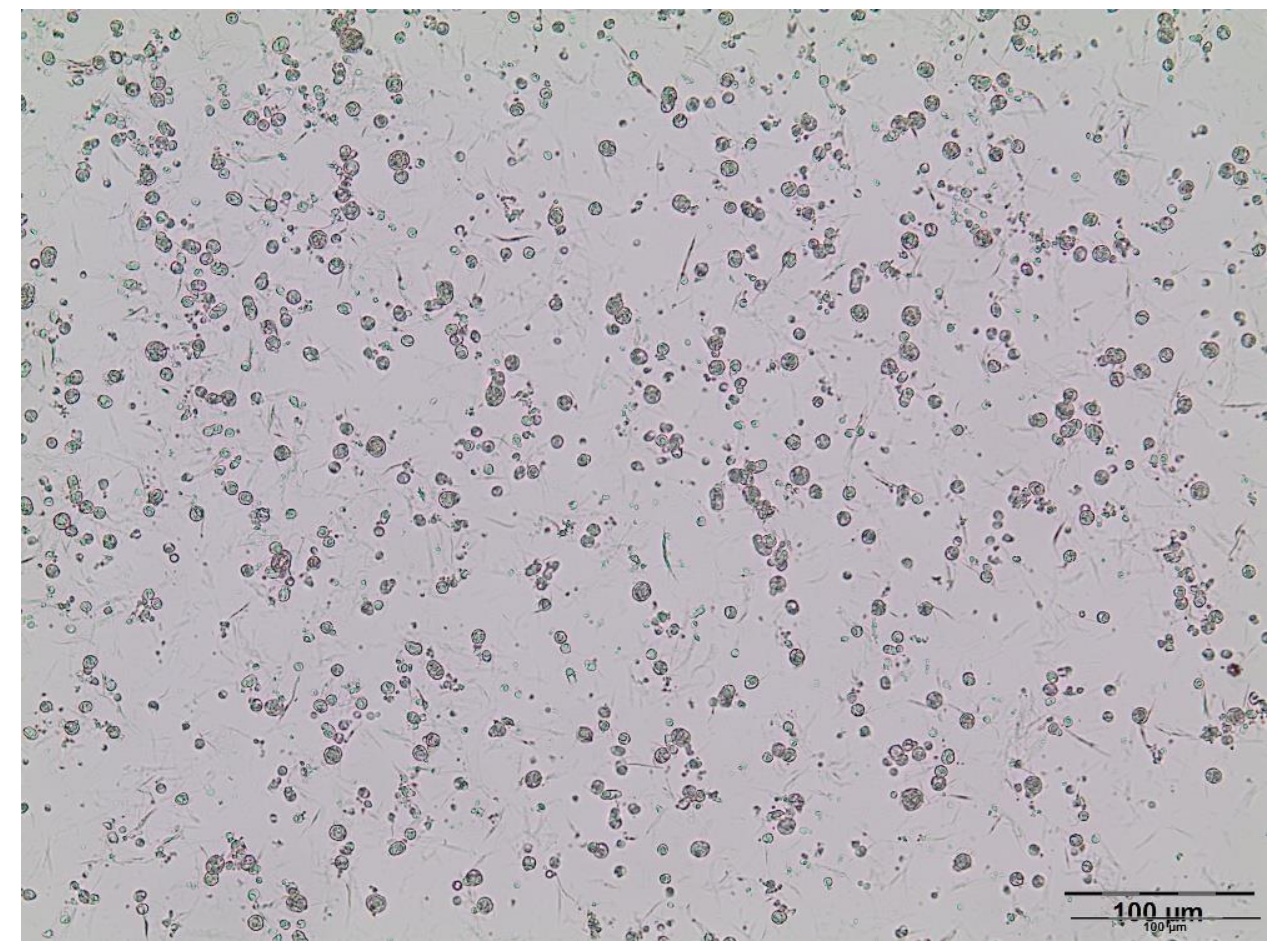

Figure 2. Photomicrograph of double $(\mathrm{W} / \mathrm{O} / \mathrm{W})$ emulsion $\mathrm{D}$.

\subsubsection{Yield and Encapsulation Efficiency}

The yield of solid lipid microparticles was very high for all investigated formulations (formulations A-D), indicating the appropriate materials and effective method were selected (Table 3). Furthermore, the encapsulation efficiency of all investigated formulations was very high, above $95 \%$ of the initial amount of gentiopicroside was incorporated in the solid lipid microparticles (Table 3). Consequently, solid lipid microparticles with Gelucire ${ }^{\circledR}$ $43 / 01$, as well as with Gelucire ${ }^{\circledR} 39 / 01$ as a lipid component, were considered as optimal for encapsulation of the hydrophilic bioactive compounds such as gentiopicroside. It was suggested recently that high encapsulation efficiency in solid lipid (nano)particles with Gelucires as lipid components could be achieved due to their heterogeneous nature (saturated polyglycolized glycerides consisting of mono-, di-, and tri-glycerides and mono- and di-fatty acid esters of polyethylene glycol), which leads to more structural imperfections and the formation of more space in the lattice that enables incorporation of the active compound [29]. Previously, it was reported that carnauba wax microparticles, prepared by a multiple emulsion-melt dispersion technique, were characterized with high encapsulation efficiency (above $80 \%$ ) in the case of a water-soluble drug, i.e., pseudoephedrine hydrochloride [11]. Consequently, it was confirmed that the multiple emulsion-melt dispersion technique was a suitable method for encapsulation of the hydrophilic active substances into solid lipid microparticles without the use of an organic solvent. On the other hand, a moderately modified multiple emulsion-melt dispersion procedure was used by Peres et al. for encapsulation of the hydrophilic drug into solid lipid nanoparticles, but the encapsulation efficiency was lower (63\%) [30]. Moreover, it is known that gentiopicroside is quite unstable [31]. Despite this, the results are indicating that there was no degradation of gentiopicroside, during the production of solid lipid microparticles. It was reported that gentiopicrin and oleanolic acid were loaded simultaneously into nanostructured lipid carriers, while lower total encapsulation efficiency $(48.34 \%)$ was determined [32]. Therefore, the high encapsulation efficiency of water-soluble (bioactive compounds) gentian extract is achieved by the selection of a suitable $\mathrm{W} / \mathrm{O} / \mathrm{W}$ emulsion formulation and process parameters. 

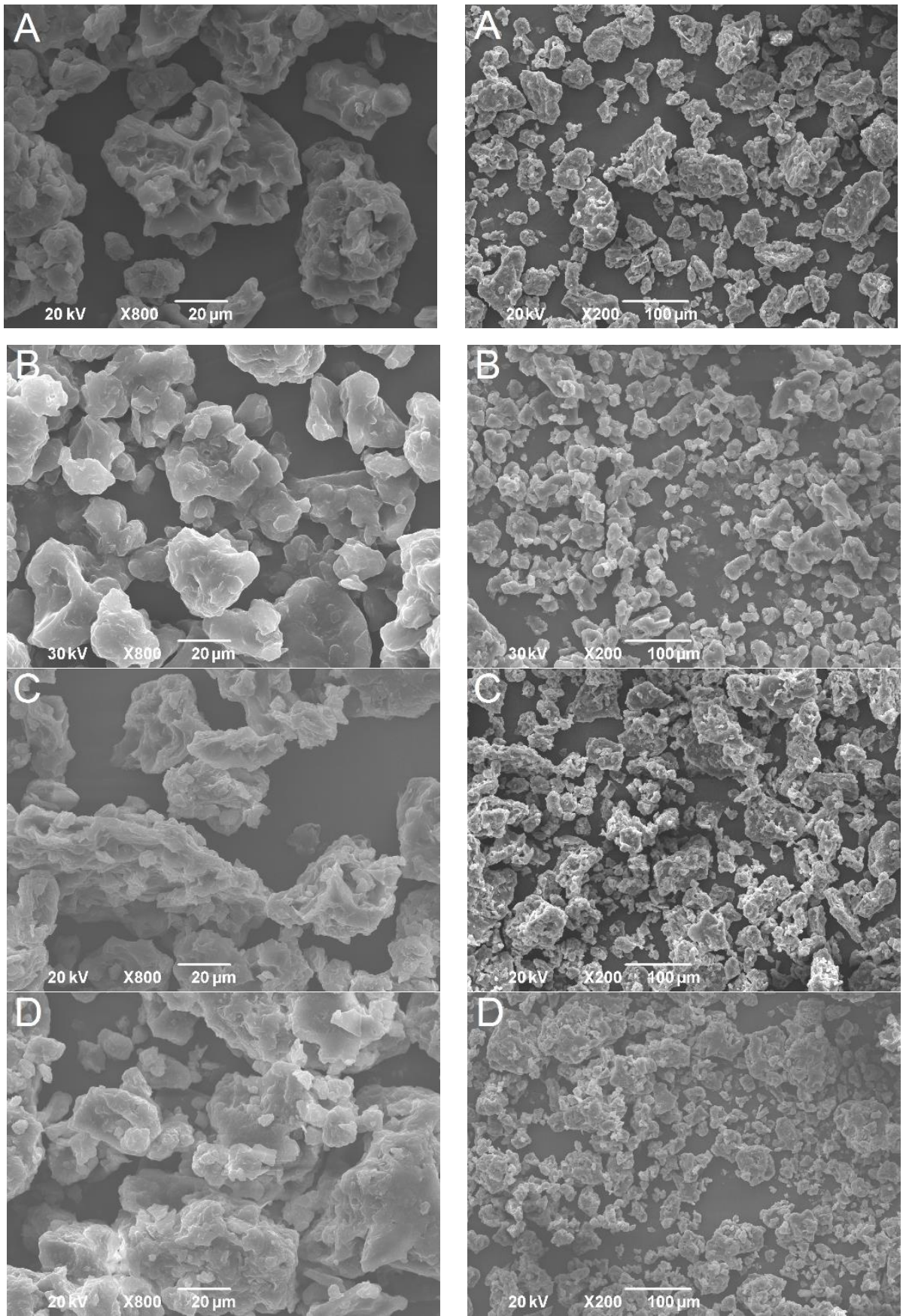

Figure 3. SEM pictures of solid lipid microparticles (formulation (A)-first row; formulation (B)-second row; formulation (C)-third row; formulation (D)-fourth row).
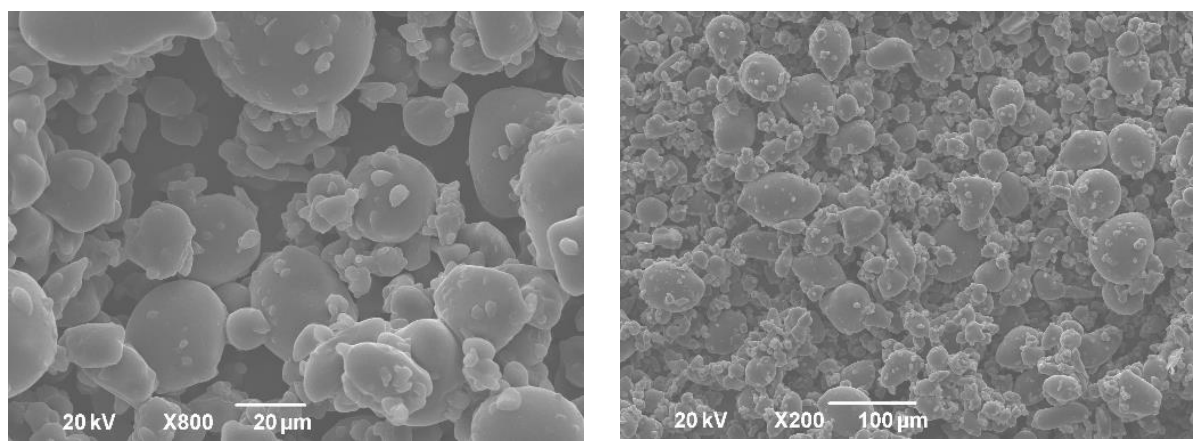

Figure 4. SEM pictures of dry gentian extract powder. 
Table 3. Encapsulation efficiency of prepared solid lipid microparticles loaded with gentian extract (A-D).

\begin{tabular}{ccccc}
\hline Sample & A & B & C & D \\
\hline EE $(\%))^{* * * *}$ & $98.92 \pm 1.06 \mathrm{a}$ & $103.02 \pm 0.15 \mathrm{ab}$ & $98.77 \pm 4.28 \mathrm{a}$ & $104.32 \pm 0.16 \mathrm{~b}$ \\
Yield (\%) ${ }^{* *}$ & $92.05 \pm 1.48 \mathrm{a}$ & $95.17 \pm 1.03 \mathrm{a}$ & $91.85 \pm 2.03 \mathrm{a}$ & $93.57 \pm 1.87 \mathrm{a}$ \\
\hline *EE-gentiopicroside encapsulation efficiency; ${ }^{* *}$ Means followed by the same letters (a or b) in the same row are \\
not significantly different according to ANOVA (Tukey's test), $p \leq 0.05$.
\end{tabular}

\subsubsection{Porosity}

The porosity of investigated powders, i.e., dry gentian extract and solid lipid microparticles loaded with gentian extract, was examined by mercury intrusion porosimetry. Properties of the obtained powders are shown in Table 4. Dry gentian extract exhibited the highest bulk density $\left(1.22 \mathrm{~g} / \mathrm{cm}^{3}\right)$, while the bulk density of formulated solid lipid microparticles was lower $\left(0.93-1.03 \mathrm{~g} / \mathrm{cm}^{3}\right)$. Moreover, solid lipid microparticle powders (A-D) floated on the simulated gastric fluid $(0.1 \mathrm{M} \mathrm{HCl})$ surface, while the gentian extract was dissolved immediately after the contact with the medium, and flotation was not realized. Generally, powders with a density lower than the density of the gastric fluid $\left(1.004 \mathrm{~g} / \mathrm{cm}^{3}\right)$ could be considered as floating delivery systems [7]. The lower bulk density of solid lipid microparticles could be attributed to the porosity of the obtained powders and the composition of particles. It was reported that Gelucire ${ }^{\circledR} 43 / 01$ (true density $0.0856 \mathrm{~g} / \mathrm{cm}^{3}$ ) and Gelucire ${ }^{\circledR} 39 / 01$ are lipid materials with low density $[13,14]$. The porosity of solid lipid microparticles in the first run was in the range from $24.7 \%$ to $32.8 \%$, whereas the porosity determined in the second run was lower and varied within the range of $16.2 \%$ and $21.3 \%$. The second run was conducted to remove the eventual influence of interparticle and intraparticle effect, which can result in apparent porosity. It was evident that the mercury intruded volume in the second run decreased, which can indicate, firstly, the interparticle porosity according to the nature of materials, and, secondly, the presence of a special pore type in the literature known as ink bottle-shaped [33]. Such shaped pores cannot discharge during the extrusion phase in the first run, wherein they remain occupied by mercury and are unavailable for the next intrusion cycle. According to the SEM micrographs, it could be realized that the porosity of solid lipid microparticles is attributed to the surface porosity, whereas the reduction in porosity in the second run could be attributed to the interparticle porosity and presence of ink bottle-shaped pores. On the other hand, the porosity of dry gentian extract in the second run was significantly lower $(3.1 \%)$ than in the first run $(20.2 \%)$, indicating the intensive presence of interparticle porosity characteristic of powder samples. The non-porous nature of dry gentian extract was confirmed by SEM micrographs (Figure 4). It is reported that porous microparticles can remain buoyant in gastric content, resulting in prolonged gastric residence time [34]. Therefore, this result indicates that formulated porous solid lipid microparticles are promising gastroretentive delivery systems. Furthermore, the average pore size of formulated solid lipid microparticles corresponds to large pore diameter, suggesting that macroporous materials are obtained [34]. The highest porosity after the first run was observed in the case of formulations with $1 \%$ of Sylysia ${ }^{\circledR} 350$ (B and D), whereas formulation D was characterized with the highest porosity in the second run and the lowest bulk density $\left(0.93 \mathrm{~g} / \mathrm{cm}^{3}\right)$. This result could be related to the high porosity of Sylysia ${ }^{\circledR} 350$ [35].

\subsubsection{Flowability}

A continuous and uniform flow of the powders is required during the production of tablets, as well as other solid dosage forms, in order to provide accurate dosing. Therefore, Carr's index (Compressibility index) and the Hausner ratio of all powder formulations were investigated. The results, presented in Table 5, revealed that formulated powders (A-D) were characterized with fair to excellent flowability according to the European Pharmacopoeia [1]. On the other hand, the dry gentian extract showed poorer properties, possibly as a result of the amorphous structure and unfavorable physicochemical and 
mechanical properties of dry herbal extracts that could cause the poor flowability of powders and compressibility in the tablet compression process [36]. Therefore, this result indicates that encapsulation of the extract in the double emulsion prior to freeze-drying improves the processability of this material.

Table 4. Average pore diameter, bulk density, and porosity of powders A-D (solid lipid microparticles) and dry gentian extract.

\begin{tabular}{ccccc}
\hline Sample & Run & $\mathbf{D}_{\mathbf{a v}}(\mu \mathbf{m})$ & BD $\left(\mathbf{g} / \mathbf{c m}^{\mathbf{3}}\right)$ & $\mathbf{P ~ ( \% )}$ \\
\hline \multirow{2}{*}{ A } & I & 9.78 & 1.03 & 24.7 \\
& II & 9.78 & 1.03 & 16.2 \\
B & I & 9.78 & 0.95 & 32.8 \\
& II & 9.00 & 0.95 & 16.7 \\
C & I & 6.29 & 0.93 & 29.9 \\
& II & 9.78 & 0.93 & 17.3 \\
D & I & 9.0 & 0.93 & 32.4 \\
& II & 9.0 & 0.93 & 21.3 \\
\multirow{2}{*}{ Dry gentian extract } & I & 9.8 & 1.22 & 20.2 \\
& II & 0.01 & 1.22 & 3.1 \\
\hline Dav-Pore diameter average; BD-Bulk density; P-porosity. & &
\end{tabular}

Table 5. Flowability of obtained solid lipid microparticles (A-D) and dry gentian extract.

\begin{tabular}{cccc}
\hline Sample & Hausner Ratio & Carr Index (\%) & Flowability \\
\hline A & $1.13 \pm 0.04$ & $11.84 \pm 3.11$ & good \\
B & $1.23 \pm 0.02$ & $18.67 \pm 1.26$ & fair \\
C & $1.10 \pm 0.02$ & $9.73 \pm 1.48$ & excellent \\
D & $1.12 \pm 0.03$ & $10.64 \pm 2.18$ & good \\
Dry gentian extract & $1.28 \pm 0.08$ & $21.95 \pm 5.26$ & passable \\
\hline
\end{tabular}

Generally, Sylysia ${ }^{\circledR} 350$ is added externally in the tablet's formulation in order to improve powder flowability [37]. However, according to the obtained results, formulations A and C (without Sylysia ${ }^{\circledR} 350$ ) were considered superior in comparison to the same formulations with $1 \%$ of Sylysia ${ }^{\circledR} 350$ (B and D). Furthermore, it was reported that the addition of colloidal silicon dioxide (Aerosil ${ }^{\circledR}$ ) to the solid dispersion of Gelucire ${ }^{\circledR} 44 / 14$ and curcumin influenced the angle of repose significantly [38], indicating that the flowability of powders was reduced, similar to our results.

\subsubsection{Mechanical Properties}

It was necessary to examine the mechanical properties of formulated powders in order to provide material with the optimal characteristics for tablet production, transport, and application. Previously, Gelucire ${ }^{\circledR}$ 43/01 and Gelucire ${ }^{\circledR}$ 39/01 were employed as releaseretarding agents and melting binders in tablet formulation, but the mechanical properties of those powders were not investigated $[39,40]$. Results revealed that the tensile strength of tablets manufactured under low compression pressure (approximately 10-50 MPa) was in the range from 0.4 to $1.5 \mathrm{MPa}$ (Figure 5a). Tablets compressed under the pressure below $10 \mathrm{MPa}$ were too fragile, and tablet hardness was not measurable by the applied hardness tester. In general, the desired tablet tensile strength should be higher than $1 \mathrm{MPa}$ [41]. The tensile strength of tablets manufactured by direct compression of powders A-C was similar under the same compression pressure, while tablets manufactured from powder D were characterized with higher tensile strength.

Furthermore, ejection (Figure $5 c$ ) and detachment stress (Figure $5 b$ ) were investigated as parameters that are used to describe the lubricating properties of tableting material. Generally, these parameters are affected by the type of tableting material and compression pressure, as well as by the finish and chemical nature of the tablet punch. Examined tablets of all investigated formulations were characterized with very low ejection stress ( 0.09 to $0.26 \mathrm{MPa}$ ) in the considered compression pressure range. According to the literature, ejection stress should be lower than $3 \mathrm{MPa}$ to prevent failure during tablet produc- 
tion $[18,42]$. Consequently, this result indicated that there was no need for the addition of a lubricant in any of the investigated formulations. Moreover, the detachment stress of formulated tablets was examined since high detachment stress could be an indicator of interaction (adhesion or stickiness) between the powder and die surface [18]. According to the previous reports, detachment stress could be lower or higher in comparison with ejection stress. Drastically higher detachment than ejection stress could reveal significant interaction of the powder and die material. In the Figure $5 b, c$ it is shown that similar or slightly higher detachment than ejection stress was determined in the case of formulations $\mathrm{B}$ and D. On the other hand, in the case of formulations $\mathrm{A}$ and $\mathrm{C}$, an increase in detachment stress was evident under a pressure greater than $50 \mathrm{MPa}$. This result suggests that formulations with Sylysia ${ }^{\circledR} 350$ were characterized with lower detachment stress and minor differences between detachment and ejection stress. Consequently, tablets manufactured by the compression of powder $\mathrm{D}$ under low pressure (23-50 MPa) were characterized with sufficient tensile strength ( $\geq 1 \mathrm{MPa}$ ) and low detachment and ejection stress. This result suggests that this formulation could be used in the production of tablets based on solid lipid microparticles loaded with gentian extract by direct compression.

\subsubsection{Mucoadhesivity Evaluation}

Mucoadhesive properties of solid dosage forms are commonly evaluated by the application of the texture analyzer measurements, whereas mucoadhesive strength is usually measured as the maximum force needed for detaching the formulation from the mucous membrane or substrate [43]. All tablets prepared by the direct compression of solid lipid microparticles loaded with gentian extract showed mucoadhesive properties. Investigated formulations (A-D) were characterized by the average force of adhesion in a range from 1.73 to $2.46 \mathrm{~N}$, as presented in Table 6, and there was no significant difference $(p=0.506)$ between formulations. The force of adhesion of $0.94 \mathrm{~N}$ was reported in the case of the optimized gastroretentive delivery system for allopurinol based on a combined approach of mucoadhesion and floating, and this system has enabled gastroretention in vivo, using the albino rabbits model [44]. The high force of adhesion of formulated tablets could be attributed to the presence of sodium alginate since it was described as an anionic mucoadhesive polymer with higher mucoadhesive strength than polymers such as polystyrene, carboxymethylcellulose, and poly (lactic acid) [45]. Moreover, it was observed that Gelucire ${ }^{\circledR}$ 43/01 and 39/01 have no adhesive properties but function as a structural agent that helps in the formation of a more robust gel and, consequently, better adhesion of tablets with hydroxypropyl methylcellulose and chitosan as hydrophilic polymers [21]. Therefore, the developed tablets are considered as mucoadhesive systems, and it could be expected that these systems are able to prolong retention time at the targeted place (i.e., stomach) and to provide intimate contact between the dosage form and the gastric mucosa.

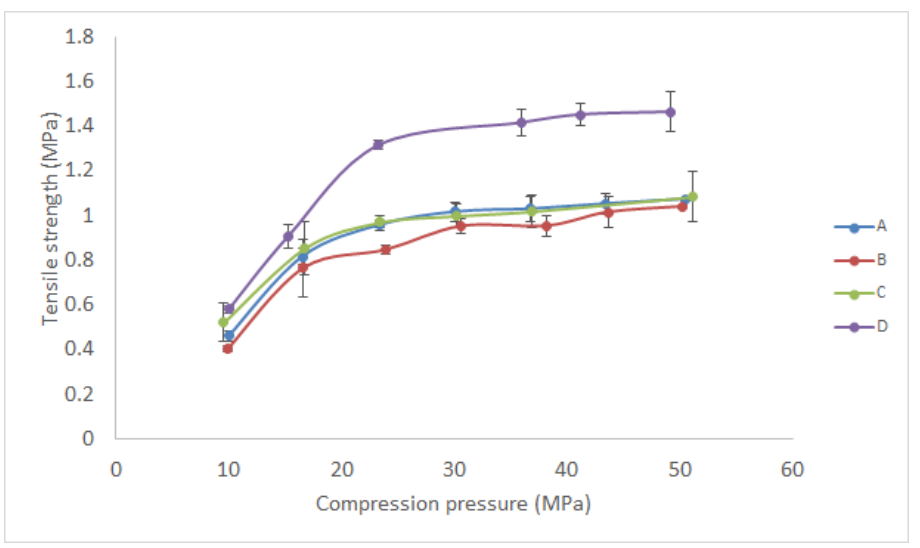

(A)

Figure 5. Cont. 


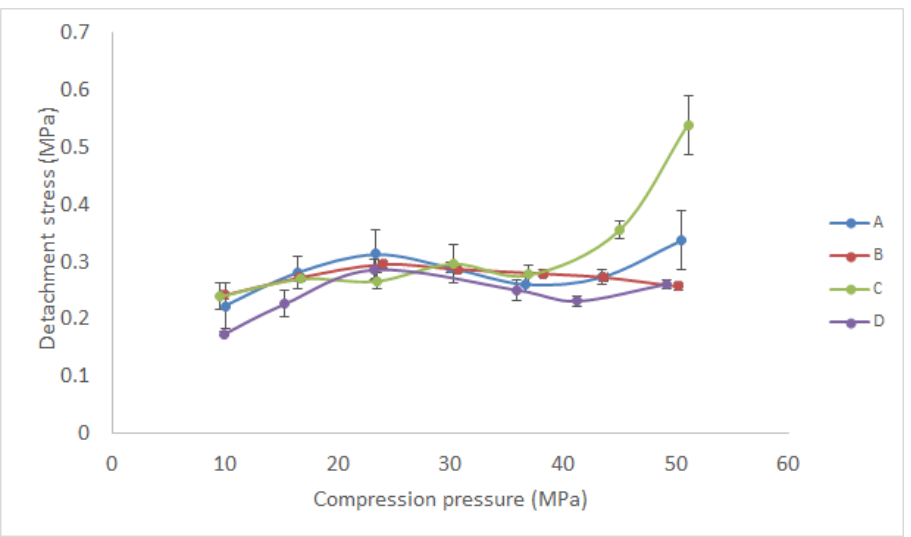

(B)

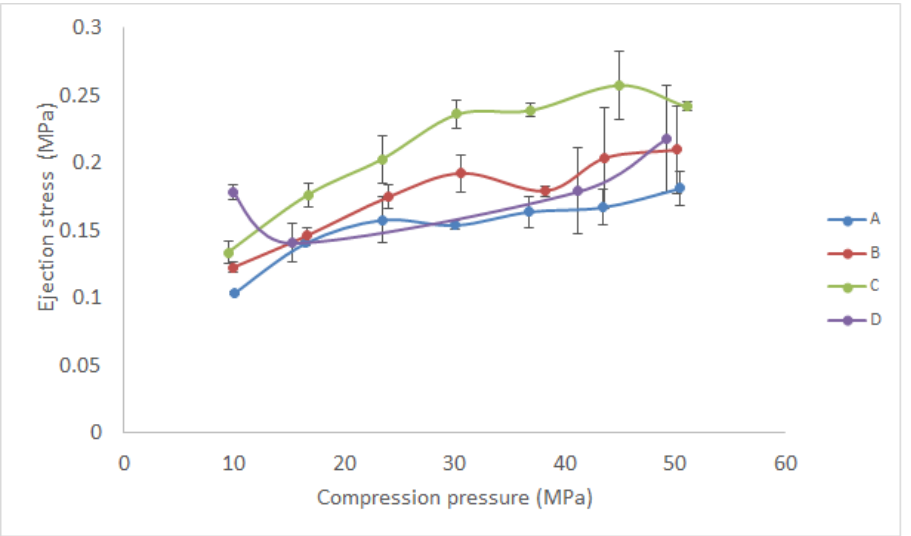

(C)

Figure 5. Tableting properties of the investigated materials compressed under different compression pressures: (A) tensile strength; (B) detachment stress; (C) ejection stress.

Table 6. The force of adhesion of tablets manufactured by direct compression of powders A-D.

\begin{tabular}{ccccc}
\hline Sample & A & B & C & D \\
\hline The force of adhesion $(\mathrm{N}) *$ & $1.73 \pm 0.66 \mathrm{a}$ & $2.02 \pm 0.46 \mathrm{a}$ & $2.08 \pm 0.64 \mathrm{a}$ & $2.46 \pm 0.12 \mathrm{a}$
\end{tabular}

${ }^{*}$ Means followed by the same letter (a) in the same row are not significantly different according to ANOVA (Tukey's test), $p \leq 0.05$.

\subsubsection{In Vitro Gentiopicroside Release}

Dissolution profiles of gentiopicroside from solid lipid microparticles loaded with gentian extract in the form of tablets, as well as from the dry gentian extract powder are presented in Figure 6. The rapid dissolution of gentiopicroside from dry gentian extract was evident. It was shown that after $15 \mathrm{~min}$, gentiopicroside was completely dissolved. This result is expected due to the high solubility of gentiopicroside. On the other hand, dissolution profiles of gentiopicroside from solid lipid microparticles loaded with gentian extract $(A-D)$ were significantly different in comparison to the dry gentian extract. Formulations A-D were characterized with the biphasic release, exhibiting burst release of gentiopicroside in the first $45 \mathrm{~min}$ and slower release in the second phase (until $6 \mathrm{~h}$ ). Therefore, it could be expected that the initial (effective) dose of extract would be dissolved in the first $45 \mathrm{~min}$, while the sustained release in the next $5-6 \mathrm{~h}$ could provide the prolonged effect of the gentian extract in the stomach, due to the previously explained mucoadhesive properties and floating ability of investigated tablets during the in vitro dissolution testing. This type of release was described previously in the case of solid lipid microparticles [9]. The sustained release of gentiopicroside indicated the effective incorporation of gentian extract inside the particle matrix. Furthermore, it could be suggested that the composition of solid lipid microparticles influenced the release rate since Gelucire ${ }^{\circledR} 39 / 01$ and 43/01 were 
used as release-retarding hydrophobic excipients in the formulation of sustained floating multiparticulate delivery systems $[13,40]$. Additionally, under acidic conditions, sodium alginate is transformed into a hydrogel that controls the release of active compounds [46]. On the other hand, rapid release in the first phase could be influenced by the porous structure and presence of gentiopicroside on the surface of solid lipid microparticles. It was reported that the porous structure of microparticles could provide a shorter pathway for the movement of bioactive compounds and water molecules [14].

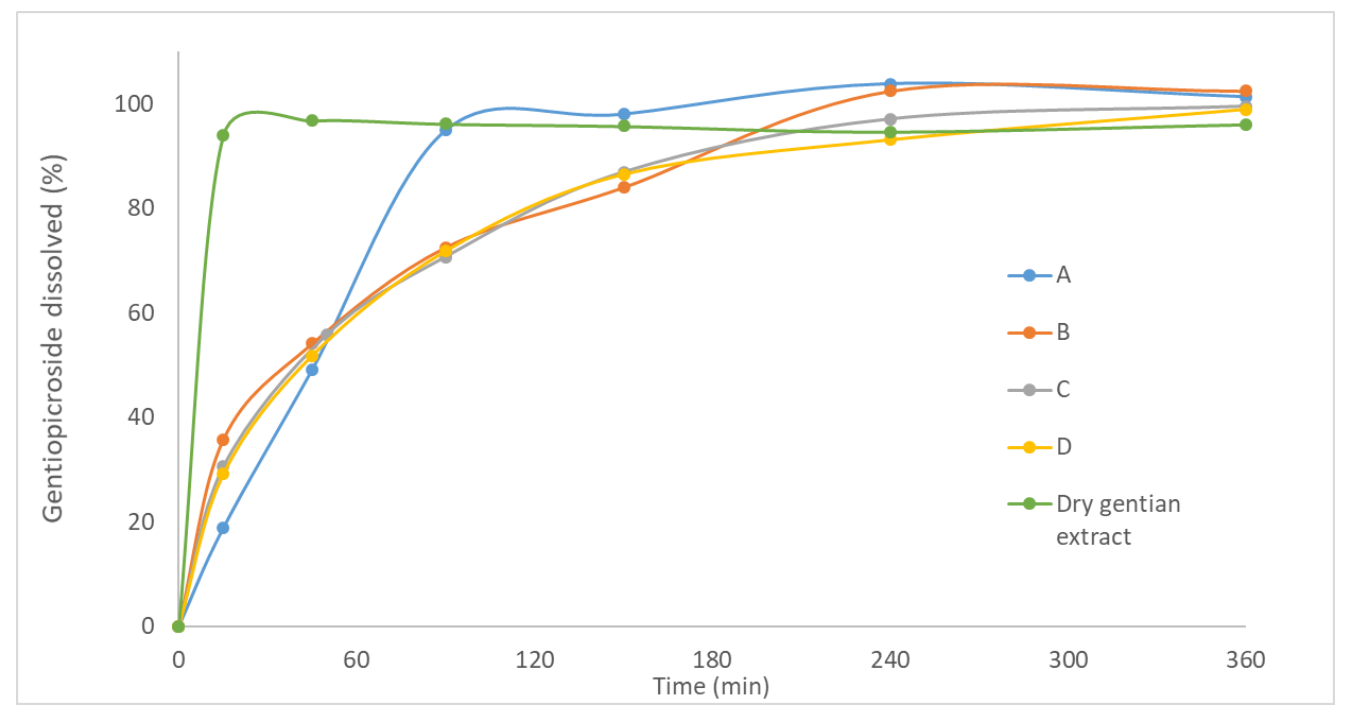

Figure 6. The dissolution profile of gentiopicroside from investigated formulations (A-D) of tablets and dry gentian extract powder.

The dissolution profiles of gentiopicroside from formulations (A and B) with the Gelucire ${ }^{\circledR} 39 / 01$ as a lipid component were different (Figure 6), indicating that the presence of Sylysia ${ }^{\circledR} 350$ (1\%) in the formulation B decreased the dissolution rate of gentiopicroside. This result is consistent with previous findings, where the addition of colloidal silicon dioxide resulted in a slower release of curcumin from self-microemulsifying drug delivery systems incorporated in gastroretentive alginate-based composite sponges [46]. Furthermore, the slower release of propranolol from the physical mixture of Eudragit RS and colloidal silicon dioxide suggested that the binding between colloidal silicon dioxide and the active compound managed to reduce the dissolution rate [47]. On the other hand, the dissolution profiles of formulations $\mathrm{C}$ and $\mathrm{D}$ were similar, indicating that the addition of Sylysia ${ }^{\circledR} 350$ influenced the dissolution rate of gentiopicroside only in the case of lipid with a lower melting point (Gelucire ${ }^{\circledR}$ 39/01).

Furthermore, according to the obtained results $\left(f_{2}<65\right)$, dissolution profiles of formulations A and C, as well as dissolution profiles of formulations B and D were not similar. A slower release rate was accomplished in the formulation with Gelucire ${ }^{\circledR} 43 / 01$ than in the formulation with Gelucire ${ }^{\circledR} 39 / 01$, indicating that the selection of the lipid component could have a significant influence on the dissolution rate of gentiopicroside. It was reported previously that the softening of the Gelucire ${ }^{\circledR}$ is a crucial factor for controlling the active compound release and that release rate was higher in granules with Gelucire ${ }^{\circledR} 39 / 01$ than in granules with Gelucire ${ }^{\circledR} 43 / 01$ [21].

Finally, the correlation coefficients $\left(\mathrm{r}^{2}\right)$ obtained after the adjustment of dissolution test experimental data to different mathematical models (zero-order, first-order, Higuchi, and Korsmeyer-Peppas) are presented in Table 7. The Korsmeyer-Peppas model was considered to be the most suitable model for describing the release kinetics of gentiopicroside from all formulations of solid lipid microparticles loaded with gentian extract in the form of tablets. Furthermore, all formulations had release exponent $(n)$ below 0.45 , suggesting that gentiopicroside was released from tablets dominantly by following the Fickian diffusion mechanism. This result is consistent with previous findings, where the Korsmeyer-Peppas 
model was applied to characterize the release mechanism of clopidogrel bisulfate from prepared Gelucire ${ }^{\circledR} 43 / 01$ microcarriers, while the $n$ value indicated that the Fickian diffusion mechanism was dominant [14].

Table 7. Correlation coefficients obtained when experimental data are fitted to different models.

\begin{tabular}{ccccc}
\hline Sample & \multicolumn{4}{c}{ Correlation Coefficients $\mathbf{( r}^{\mathbf{2}} \mathbf{~}$} \\
\hline & Zero-order & First-order & Higuchi & Korsmeyer-Peppas \\
A & 0.6241 & 0.4783 & 0.8422 & 0.8524 \\
B & 0.7433 & 0.7319 & 0.9423 & 0.9819 \\
C & 0.7268 & 0.6628 & 0.9339 & 0.9601 \\
D & 0.7279 & 0.6600 & 0.9339 & 0.9601 \\
\hline
\end{tabular}

\subsubsection{Dispersibility during In Vitro Dissolution}

Figure 7 shows the size distributions of dispersions obtained and sampled during the in vitro dissolution testing for the tested samples $A-D$, and in Table 8 the size diameters corresponding to each peak and their intensity are summarized.

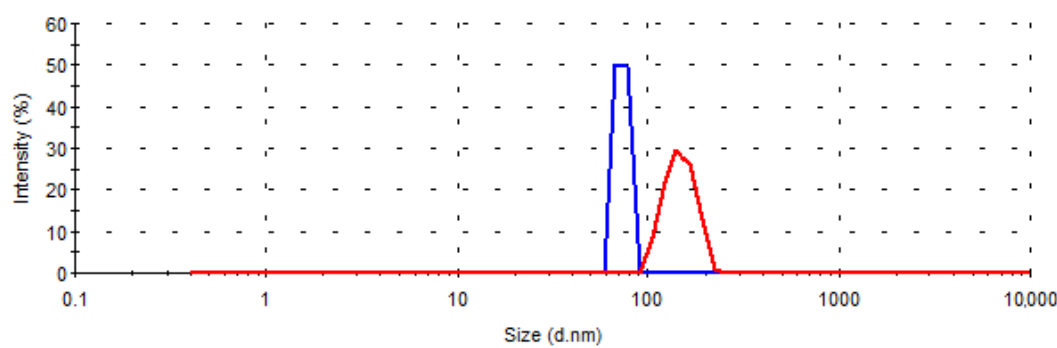

(A)

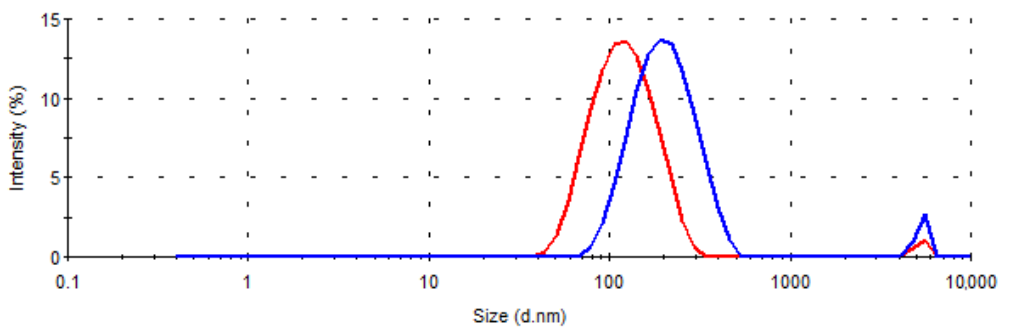

(B)

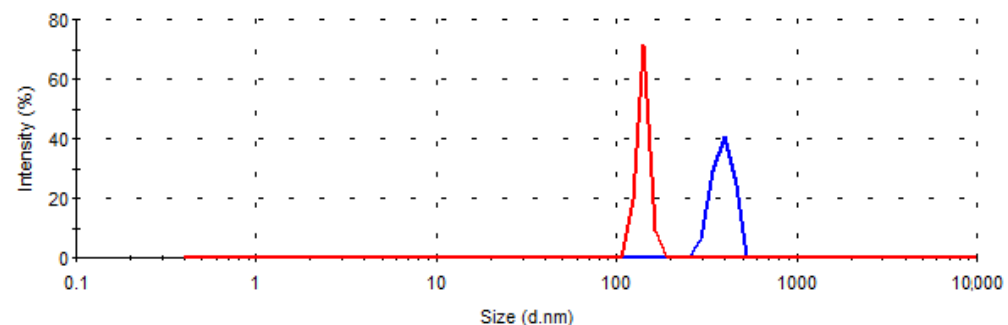

(C)

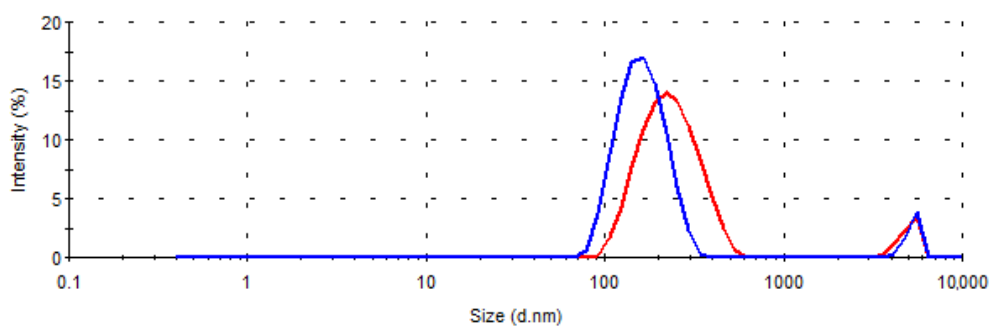

(D)

Figure 7. Size distribution by intensity in the dissolution media samples collected after 15 min (-) and $6 \mathrm{~h} \mathrm{(-)}$ for the tablets (A-D). 
Table 8. The diameter and intensity of the peaks in size distribution curves obtained for the samples of the dissolution medium during the in vitro drug release testing of the tablets A-D.

\begin{tabular}{ccccccccc}
\hline Time & \multicolumn{3}{c}{15 min } & \multicolumn{3}{c}{ 6 h } \\
\hline Peak & \multicolumn{2}{c}{ Peak 1 } & \multicolumn{2}{c}{ Peak 2 } & \multicolumn{2}{c}{ Peak 1 } & \multicolumn{2}{c}{ Peak 2 } \\
Sample & $\mathrm{D}(\mathrm{nm})$ & $\mathrm{I}(\%)$ & $\mathrm{D}(\mathrm{nm})$ & $\mathrm{I}(\%)$ & $\mathrm{D}(\mathrm{nm})$ & $\mathrm{I}(\%)$ & $\mathrm{D}(\mathrm{nm})$ & $\mathrm{I}(\%)$ \\
A & 73.4 & 100.0 & $/$ & $/$ & 147.4 & 100.0 & $/$ & $/$ \\
B & 210.2 & 96.3 & 5319.0 & 3.7 & 126.4 & 98.2 & 5236.0 & 1.8 \\
C & 389.6 & 100.0 & $/$ & $/$ & 140.1 & 100.0 & $/$ & $/$ \\
D & 165.5 & 94.1 & 5271.0 & 5.9 & 239.3 & 93.0 & 5007.0 & 7.0 \\
\hline D—Diameter; I-Intensity & & & & & & &
\end{tabular}

In all tested samples, after only $15 \mathrm{~min}$, nanoassociates of size less than $500 \mathrm{~nm}$ were observed. In addition, at this time point, in the medium in which the tablets of samples $\mathrm{B}$ and $\mathrm{D}$ were tested, the presence of microparticles of about $5 \mu \mathrm{m}$ in size was detected, which most likely represents the silica (Sylysia ${ }^{\circledR} 350$ ) added to these two formulations. The average Sylysia ${ }^{\circledR} 350$ particle size, according to the manufacturer's specification is $3.9 \mu \mathrm{m}$ [48], and increased silica particle size could be the consequence of liquid $\mathrm{W} / \mathrm{O} / \mathrm{W}$ emulsion absorption [16].

Differences in the dispersibility of solid lipid microparticles were most pronounced at the very beginning of the dissolution test. The smallest size of nanoassociates was present in the dissolution medium samples of tablets $\mathrm{A}$, which could indicate faster dispersion of microparticles from tablets A and, consequently, coincide with the observed higher rate of gentiopicroside release compared to other formulations. The nanoassociates were present in the dissolution medium samples even after $6 \mathrm{~h}$ for all tested formulations (Figure 7, Table 8). The observed presence of the surfactant and lipid-based nanoassociates in the medium corresponding to an acidic environment in the stomach may be advantageous for a prospective increase in the absorption of the bioactive compound in vivo [49].

\section{Conclusions}

An effective method for the encapsulation of gentian extract into solid lipid microparticles was developed by freeze-drying double $(\mathrm{W} / \mathrm{O} / \mathrm{W})$ emulsions with solid lipid, i.e., Gelucire ${ }^{\circledR} 39 / 01$ or $43 / 01$, with polyglycerol ployricinoleate as lipophilic emulsifier and lecithin as a hydrophilic emulsifier. Moreover, this organic solvent-free method could be highly beneficial for the encapsulation of other liquid extracts or bioactive compounds in an advanced carrier, which could enable modified release.

All investigated solid lipid microparticle formulations were characterized with very high yield (above 90\%) and gentiopicroside (marker compound) encapsulation efficiency (above 95\%), demonstrating that the developed technique was suitable for the encapsulation of hydrophilic bioactive compounds into solid lipid microparticles without the use of organic solvent. Furthermore, SEM analysis and mercury intrusion porosimetry revealed that solid lipid microparticles with the macroporous structure were formulated, and, consequently, the powders floated immediately in the acidic medium $(0.1 \mathrm{M} \mathrm{HCl})$. On the other hand, freeze-dried gentian extract was a non-porous powder, which was immediately dissolved in the same medium. Formulated powders have shown fair to excellent flowability according to the European Pharmacopoeia, while dry gentian extract has shown poorer properties, indicating that the encapsulation of an extract in the double emulsion before freeze-drying has improved the processability of this material. During the direct compression of formulated powders, it was evident that the addition of lubricant was not necessary. All tablets prepared by the direct compression of solid lipid microparticles loaded with gentian extract have shown mucoadhesive properties. Finally, in vitro dissolution tests have shown that the biphasic release of gentiopicroside from formulated solid lipid microparticles in the form of tablets was achieved. Therefore, the prolonged effect of the gentian extract in the stomach could be expected, due to mucoadhesive properties and the floating ability of the investigated formulations, while the presence of the surfactant 
and lipid-based nanoassociates could suggest the increase in the absorption of bioactive compounds in vivo.

In addition, formulation D with porous silica $\left(\right.$ Sylysia $\left.^{\circledR} 350\right)$ and Gelucire ${ }^{\circledR} 43 / 01$ as a solid lipid was characterized with the hight yield end encapsulation efficiency, as well as with the highest porosity and the lowest bulk density $\left(0.93 \mathrm{~g} / \mathrm{cm}^{3}\right)$ among the investigated formulations. The flowability of this formulation was good according to the European Pharmacopoeia, while the detachment, ejection stress, and tensile strength of manufactured tablets were optimal, suggesting that this formulation could be used in the production of tablets by direct compression. Furthermore, the mucoadhesive properties of the formulation $\mathrm{D}$ in the form of tablets, as well as the biphasic release of gentiopicroside and presence of nanoassociates indicate that a promising lipid-based gastroretentive carrier for the site-specific delivery of gentian extract was developed. In further studies, it would be essential to investigate the bioavailability of developed formulation.

Author Contributions: Conceptualization J.M., J.Đ. and K.Š.; methodology, J.M., S.P., I.K. and L.Đ.; validation, J.Đ., L.Đ. and S.I.; formal analysis, J.M.; investigation, J.M., L.Đ., S.P. and I.K.; resources, S.I. and K.S..; data curation, J.Đ.; writing—original draft preparation, J.M.; writing—review and editing,

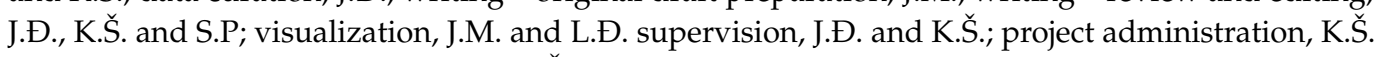
and S.I.; funding acquisition, S.I. and K.S.S. All authors have read and agreed to the published version of the manuscript.

Funding: This research was funded by the Ministry of Education, Science and Technological Development of the Republic of Serbia (contract numbers 451-03-9/2021-14/200003 and 451-03-9/202114/200161).

Institutional Review Board Statement: Not applicable.

Informed Consent Statement: Not applicable.

Data Availability Statement: All data generated during the research are included in this manuscript. Further details and support are available from the corresponding author on the request.

Acknowledgments: The authors would like to thank PVP-Centre for Lyophilization (Valjevo, Serbia). Gelucires used in this study were kind gift from Gattefosse ${ }^{\circledR}$ (Saint-Priest, France) and PGPR was a kind gift of Palsgaard ${ }^{\circledR}$ (Juelsminde, Denmark). Additionally, we wish to thank Tara Đurđević for the graphical support of this paper (Figure 1 and graphical abstract).

Conflicts of Interest: The authors declare no conflict of interest.

\section{References}

1. Council of Europe. European Pharmacopoeia, 10th ed.; European Directorate for the Quality of Medicines \& Health Care of the Council of Europe: Strasbourg, France, 2019.

2. Tasić, S. Ethnobotany in SEE-WB countries; traditional uses of indigenous plants. Lek. Sirovine 2012, 32, 71-81.

3. Šavikin, K.; Aljančić, I.; Vajs, V.; Milosavljević, S.; Jadranin, M.; Đordević, I.; Menković, N. Bioactive secondary metabolites in several genera of Gentianaceae species from the central regions of the Balkan Peninsula. In The Gentianaceae Volume 2: Biotechnology and Applications; Rybczynski, J., Davey, M., Mikuła, A., Eds.; Springer: Berlin, Germany, 2015; Volume 3, pp. $319-347$.

4. Jiang, M.; Cui, B.W.; Wu, Y.L.; Nan, J.X.; Lian, L.H. Genus Gentiana: A review on phytochemistry, pharmacology and molecular mechanism. J. Ethnopharmacol. 2021, 264, 113391. [CrossRef]

5. Wang, C.-H.; Wang, Z.-T.; Annie Bligh, W.W.; White, K.N.; White, C.J.B. Pharmacokinetics and tissue distribution of gentiopicroside following oral and intravenous administration in mice. Eur. J. Drug Metab. Pharmacokinet. 2004, 29, 199-203. [CrossRef]

6. European Medicines Agency, Assessment Report on Gentiana lutea L., Radix. Ref.: EMA/HMPC/607863/2017. Available online: https:/ / www.ema.europa.eu/en/documents/herbal-report/assessment-report-gentiana-lutea-1-radix-revision-1_en.pdf (accessed on 28 October 2021).

7. Lopes, C.M.; Bettencourt, C.; Rossi, A.; Buttini, F.; Barata, P. Overview on gastroretentive drug delivery systems for improving drug bioavailability. Int. J. Pharm. 2016, 510, 144-158. [CrossRef] [PubMed]

8. Yadav, V.R.; Suresh, S.; Devi, K.; Yadav, S. Novel formulation of solid lipid microparticles of curcumin for anti-angiogenic and anti-inflammatory activity for optimization of therapy of inflammatory bowel disease. J. Pharm. Pharmacol. 2009, 61, 311-321. [CrossRef] [PubMed]

9. Scalia, S.; Young, P.M.; Traini, D. Solid lipid microparticles as an approach to drug delivery. Expert Opin. Drug Deliv. 2015, 12, 583-599. [CrossRef] 
10. Artiga-Artigas, M.; Molet-Rodríguez, A.; Salvia-Trujillo, L.; Martín-Belloso, O. Formation of double (W 1/O/W 2) emulsions as carriers of hydrophilic and lipophilic active compounds. Food Bioprocess Technol. 2019, 12, 422-435. [CrossRef]

11. Bodmeier, R.; Wang, J.; Bhagwatwar, H. Process and formulation variables in the preparation of wax microparticles by a melt dispersion technique. II. W/O/W multiple emulsion technique for water-soluble drugs. J. Microencapsul. 1992, 9, 99-107. [CrossRef]

12. Leister, N.; Karbstein, H.P. Evaluating the stability of double emulsions-A review of the measurement techniques for the systematic investigation of instability mechanisms. Colloids Interfaces 2020, 4, 8. [CrossRef]

13. Chauhan, B.; Shimpi, S.H.Y.A.M.; Mahadik, K.R.; Paradkar, A. Preparation and evaluation of floating risedronate sodium Gelucire $^{\circledR}$ 39/01 matrices. Acta. Pharm. 2004, 54, 205-214.

14. Irshad, S.; Khan, I.U.; Khalid, S.H.; Asghar, S.; Irfan, M.; Khalid, I.; Shahzad, Y. Probing the effect of various lipids and polymer blends on clopidogrel encapsulated floating microcarriers. DARU J. Pharm. Sci. 2019, 27, 571-582. [CrossRef]

15. Dhawan, V.; Sutariya, B.; Lokras, A.; Thamm, J.; Saraf, M.; Warawdekar, U.; Nagarsenker, M. Lipid nanoconstructs for superior hepatoprotection: In vitro assessments as predictive tool for in vivo translation. Int. J. Pharm. 2020, 579, 119176. [CrossRef]

16. Seljak, K.B.; Ilić, I.G.; Gašperlin, M.; Pobirk, A.Z. Self-microemulsifying tablets prepared by direct compression for improved resveratrol delivery. Int. J. Pharm. 2018, 548, 263-275. [CrossRef] [PubMed]

17. Balijagić, J.; Janković, T.; Zdunić, G.; Bosković, J.; Šavikin, K.; Gođevac, D.; Stanojković, T.; Jovančić, M.; Menković, N. Chemical profile, radical scavenging and cytotoxic activity of yellow gentian leaves (Genitaneae luteae folium) grown in northern regions of Montenegro. Nat. Prod. Commun. 2012, 7, 1487-1490. [CrossRef] [PubMed]

18. Milanovic, A.; Aleksic, I.; Ibric, S.; Parojcic, J.; Cvijic, S. Tableting of hot-melt coated paracetamol granules: Material tableting properties and quality characteristics of the obtained tablets. Eur. J. Pharm. Sci. 2020, 142, 105121. [CrossRef]

19. United States Pharmacopeial Convention. Disintegration and Dissolution of Dietary Supplements. In The United States Pharmacopeia and National Formulary USP 36-NF 31; The United States Pharmacopeial Convention, Inc.: Rockville, MD, USA, 2013; pp. 1111-1116.

20. Moore, J.W.; Flanner, H.H. Mathematical comparison of dissolution profiles. Pharm. Technol. 1996, 20, 64-74.

21. Notario-Pérez, F.; Cazorla-Luna, R.; Martín-Illana, A.; Ruiz-Caro, R.; Peña, J.; Veiga, M.D. Tenofovir hot-melt granulation using Gelucire ${ }^{\circledR}$ to develop sustained-release vaginal systems for weekly protection against sexual transmission of HIV. Pharmaceutics 2019, 11, 137. [CrossRef]

22. Matos, M.; Gutiérrez, G.; Coca, J.; Pazos, C. Preparation of water-in-oil-in-water (W1/O/W2) double emulsions containing trans-resveratrol. Colloids Surf. A Physicochem. Eng. Asp. 2014, 442, 69-79. [CrossRef]

23. Neumann, S.M.; Scherbej, I.; Van Der Schaaf, U.S.; Karbstein, H.P. Investigations on the influence of osmotic active substances on the structure of water in oil emulsions for the application as inner phase in double emulsions. Colloids Surf. A Physicochem. Eng. Asp. 2018, 538, 56-62. [CrossRef]

24. Liu, F.; Wang, Y.; Li, X.; Zhang, Z.; Dai, X.; Wang, X.; Xin, Y.; Liu, K.; Gao, L.; Du, D.; et al. The phase inversion mechanism of the $\mathrm{pH}$-sensitive reversible invert emulsion from w/o to o/w. Open Phys. 2020, 18, 380-390. [CrossRef]

25. Florence, A.T.; Whitehill, D. The formulation and stability of multiple emulsions. Int. J. Pharm. 1982, 11, 277-308. [CrossRef]

26. Ding, S.; Serra, C.A.; Vandamme, T.F.; Yu, W.; Anton, N. Double emulsions prepared by two-step emulsification: History, state-of-the-art and perspective. J. Control Release 2019, 295, 31-49. [CrossRef]

27. Mazuco, R.A.; Cardoso, P.M.M.; Bindaco, É.S.; Scherer, R.; Castilho, R.O.; Faraco, A.A.G.; Ruas, R.G.; Oliveira, J.P.; Cunegundes Guimarães, M.C.; de Andrade, T.U.; et al. Maltodextrin and gum Arabic-based microencapsulation methods for anthocyanin preservation in Juçara palm (Euterpe edulis Martius) fruit pulp. Plant Foods Hum. Nutr. 2018, 73, 209-215. [CrossRef]

28. Dolly, P.; Anishaparvin, A.; Joseph, G.S.; Anandharamakrishnan, C. Microencapsulation of Lactobacillus plantarum (mtcc 5422) by spray-freeze-drying method and evaluation of survival in simulated gastrointestinal conditions. J. Microencapsul. 2011, 28, 568-574. [CrossRef]

29. El Assasy, A.E.H.I.; Younes, N.F.; Makhlouf, A.I. Enhanced oral absorption of amisulpride via a nanostructured lipid carrierbased capsules: Development, optimization applying the desirability function approach and in vivo pharmacokinetic study. AAPS PharmSciTech 2019, 20, 1-14.

30. Peres, L.B.; Peres, L.B.; de Araújo, P.H.H.; Sayer, C. Solid lipid nanoparticles for encapsulation of hydrophilic drugs by an organic solvent free double emulsion technique. Colloids Surf. B Biointerfaces 2016, 140, 317-323. [CrossRef] [PubMed]

31. Aberham, A.; Pieri, V.; Croom Jr, E.M.; Ellmerer, E.; Stuppner, H. Analysis of iridoids, secoiridoids and xanthones in Centaurium erythraea, Frasera caroliniensis and Gentiana lutea using LC-MS and RP-HPLC. J. Pharm. Biomed. Anal. 2011, 54, 517-525. [CrossRef] [PubMed]

32. Zhang, K.; Lv, S.; Li, X.; Feng, Y.; Li, X.; Liu, L.; Li, S.; Li, Y. Preparation, characterization, and in vivo pharmacokinetics of nanostructured lipid carriers loaded with oleanolic acid and gentiopicrin. Int. J. Nanomed. 2013, 8, 3227-3239. [CrossRef]

33. Graham, D. Characterization of physical adsorption systems. III. The separate effects of pore size and surface acidity upon the adsorbent capacities of activated carbons. J. Phys. Chem. 1955, 59, 896-900. [CrossRef]

34. Dastidar, D.G.; Saha, S.; Chowdhury, M. Porous microspheres: Synthesis, characterisation and applications in pharmaceutical \& medical fields. Int. J. Pharm. 2018, 548, 34-48.

35. Kovačič, B.; Vrečer, F.; Planinšek, O. Solid dispersions of carvedilol with porous silica. Chem. Pharm. Bull. 2011, 59, 427-433. [CrossRef] [PubMed] 
36. Mudrić, J.; Arsenijević, J.; Maksimović, Z.; Ibrić, S.; Gopčević, K.; Đuriš, J. Tablet and capsule formulations incorporating high doses of a dry optimized herbal extract: The case of Satureja kitaibelii. J. Drug Deliv. Sci. Technol. 2021, 66, 102776. [CrossRef]

37. Panda, T.; Das, D.; Panigrahi, L. Formulation development of solid dispersions of bosentan using Gelucire 50/13 and Poloxamer 188. J. Appl. Pharm. Sci. 2016, 6, 27-33. [CrossRef]

38. Araújo, R.R.; Teixeira, C.C.C.; Freitas, L.A.P. The preparation of ternary solid dispersions of an herbal drug via spray drying of liquid feed. Dry. Technol. 2010, 28, 412-421. [CrossRef]

39. Madgulkar, A.R.; Bhalekar, M.R.; Padalkar, R.R. Formulation design and optimization of novel taste masked mouth-dissolving tablets of tramadol having adequate mechanical strength. AAPS PharmSciTech 2009, 10, 574-581. [CrossRef]

40. Thakkar, V.T.; Shah, P.A.; Soni, T.G.; Parmar, M.Y.; Gohel, M.C.; Gandhi, T.R. Goodness-of-fit model-dependent approach for release kinetics of levofloxacin hemihydrates floating tablet. Dissolution Technol. 2009, 16, 35-39. [CrossRef]

41. Amidon, G.E.; Secreast, P.J.; Mudie, D. Developing Solid Oral Dosage Forms; Qiu, Y., Zhang, G., Chen, Y., Liu, L., Porter, W., Eds.; Academic Press: Cambridge, MA, USA, 2009; Volume 8, pp. 163-186.

42. Pitt, K.G.; Webber, R.J.; Hill, K.A.; Dey, D.; Gamlen, M.J. Compression prediction accuracy from small scale compaction studies to production presses. Powder Technol. 2015, 270, 490-493. [CrossRef]

43. Kurćubić, I.; Cvijić, S.; Filipčev, B.; Ignjatović, J.; Ibrić, S.; Đuriš, J. Development of propranolol hydrochloride bilayer mucoadhesive buccal tablets supported by in silico physiologically-based modeling. React. Funct. Polym. 2020, 151, 104587. [CrossRef]

44. Sharma, O.P.; Shah, M.V.; Parikh, D.C.; Mehta, T.A. Formulation optimization of gastroretentive drug delivery system for allopurinol using experimental design. Expert Opin. Drug Deliv. 2015, 12, 513-524. [CrossRef]

45. Md, S.; Ahuja, A.; Khar, R.K.; Baboota, S.; Chuttani, K.; Mishra, A.K.; Ali, J. Gastroretentive drug delivery system of acyclovirloaded alginate mucoadhesive microspheres: Formulation and evaluation. Drug Deliv. 2011, 18, 255-264. [CrossRef]

46. Petchsomrit, A.; Sermkaew, N.; Wiwattanapatapee, R. Alginate-based composite sponges as gastroretentive carriers for curcuminloaded self-microemulsifying drug delivery systems. Sci. Pharm. 2017, 85, 11. [CrossRef] [PubMed]

47. Sadeghi, F.; Mosafa, F.; Afrasiabi, G.H. Effect of particle size, compaction force and presence of Aerosil 200 on the properties of matrices prepared from physical mixture of propranolol hydrochloride and eudragit RS or RL. Iran. J. Basic Med. Sci. 2007, 10, 197-205.

48. Fuji Silysia Chemical Ltd. Available online: https://www.fujisilysia.com/products/sylysia/ (accessed on 28 October 2021).

49. Cortés, H.; Hernández-Parra, H.; Bernal-Chávez, S.A.; Prado-Audelo, M.L.D.; Caballero-Florán, I.H.; Borbolla-Jiménez, F.V.; González-Torres, M.; Magaña, J.J.; Leyva-Gómez, G. Non-ionic surfactants for stabilization of polymeric nanoparticles for biomedical uses. Materials 2021, 14, 3197. [CrossRef] 